\title{
Evaluation of Nutraceutical Properties of Pleurotus ostreatus (Jacq.) P. Kumm
} (Pleurotaceae)

\section{${ }^{*}$ OKUNLOLA, GO; ${ }^{1}$ AKINYEMI, SA; ${ }^{1}$ JIMOH, MA; ${ }^{2}$ OLOWOLAJU, ED; ${ }^{1}$ AJAO, YO}

\author{
${ }^{*}$ Department of Plant Biology, Faculty of Basic and Applied Sciences, Osun State University, Osogbo, Nigeria \\ ${ }^{2}$ Department of Botany, Faculty of Science, Obafemi Awolowo University, Ile Ife, Nigeria. \\ *Corresponding Author Email: gideon.okunlola@uniosun.edu.ng
}

\begin{abstract}
Recently, consumption of mushroom is on the increase in many developing countries. They serve as food supplements in diets of the people. The present study was conducted to evaluate nutraceutical properties of the oyster mushroom (Pleurotus ostreatus), a widely cultivated mushroom in Nigeria. Properties such as proximate composition, mineral ions and antioxidants contents were analyzed using standard methods. P. ostreatus was found to contain high percentage of crude fibre, moisture content, carbohydrates, crude fat, total ash, crude protein and oil matter. Percentage of mineral ion such as sodium, calcium, potassium, magnesium, phosphorus, iron, copper and zinc were found to be lower in value. Antioxidants such as flavonoid, phenol, lycopene, $\beta$ Carotene and ascorbic acid in $P$. ostreatus were found to be high in value. Overall, the percentage content of minerals in $P$. ostreatus was less than $1 \%$, proximate composition was $33.64 \%$ and antioxidants was $66.16 \%$. This showed that $P$. ostreatus had a high content of antioxidants, moderate amount of proximate composition and low amount of minerals. As $P$. ostreatus contains low calorific value and very high content of antioxidants, dietary fibres and minerals, it can therefore be said to be potentially good for medicinal purposes especially among the vegetarian consumers
\end{abstract}

DOI: https://dx.doi.org/10.4314/jasem.v25i4.25

Copyright: Copyright $@ 2021$ Okunlola et al. This is an open access article distributed under the Creative Commons Attribution License (CCL), which permits unrestricted use, distribution, and reproduction in any medium, provided the original work is properly cited.

Dates: Received: 14 February 2021; Revised: 26 March 2021; Accepted: 12 April 2021

Keywords: Antioxidants, Diets, Minerals, Mushroom, Proximate, Nutraceutical properties

Oyster mushroom (Pleurotus ostreatus) is a macroscopic edible fungus, with a fleshy spongy and umbrella-shaped form belonging to Kingdom Fungi and Family Pleurotaceae. It exists in various sizes and is widespread in many temperate and subtropical forests throughout the world (Trudell and Ammirati, 2009). P. ostreatus grows in many places, but its other related species, such as the popular branched oyster mushroom, grow only on trees. They may be found all the year round in temperate and subtropical forests and are now grown commercially around the world for food. P. ostreatus is known as wonder 'vegetable' as they have unique growth pattern and quick multiplication and are vastly replacing green leafy vegetables in the diet of people (Adejumo and Akinmoladun, 2015). It is eaten and appreciated for their culinary flavor, economic and ecological values as well as medicinal properties for many years. It has chemical compositions which are attractive from nutritional point of view (Gbolagade et al. 2006; Dundar et al. 2008). Its nutritional values compare with those of egg, milk and meat (Oei, 2003). It is generally reported that the mushroom also contains vitamins and an abundance of essential amino acids valued in human diets (Sánchez, 2004). For centuries, traditional diets in many West African countries in general and many rural Nigerian communities in particular, are prepared using different kinds of mushrooms, $P$. ostreatus being the commonest among them (Adejumo and Akinmoladun, 2015). Just as it has been popular as food supplement for many centuries, not only for its flavor and aroma, it is also valued for medicinal properties (Patel et al., 2012; Deepalakshmi and Mirunalini, 2014). P. ostreatus was reported to have high culinary values due to its high quality proteins, vitamins, fibres and many medicinal properties and are therefore classified as notable nutraceutical (Patel et al, 2012). Nevertheless, there is dearth of information on the nutraceutical properties of this species resulting in low level of consumption, especially among people living in urban areas. This study was therefore aimed at analyzing the proximate composition, antioxidant and mineral content of $P$. ostreatus highly cultivated by mushroom growers in Nigeria, in order to elucidate on its nutraceutical properties for creating awareness on its dietary and medicinal properties in the diet of the human kind. 


\section{MATERIALS AND METHODS}

Source of $P$. ostreatus material and its identification: The study was carried out in the Department of Plant Biology, Faculty of Basic and Applied Sciences, Osun State University, Osogbo, Nigeria. The mushroom used in this study was cultivated at LTC Mushroom Farm, Ofatedo, Osun State, Nigeria and was identified as $P$. ostreatus at the Department of Microbiology, Obafemi Awolowo University, Ile Ife, Nigeria.

Preparation of samples for analysis: After cultivation, the mushrooms were handpicked, thoroughly but carefully rinsed in deionized water and sun-dried by constant exposure to sunlight at a temperature of about $35^{\circ} \mathrm{C}$ for two weeks due to the prevalent unstable and unpredictable weather during the period of the study. The prepared samples were regularly turned on the drying platform to avoid growth of obnoxious fungi on any of its parts. They were later pulverised using electric blender and stored in well-dried water-proof containers until needed for further analysis.

Determination of Proximate composition: Proximate composition of the mushroom involving crude fibre, moisture content, crude fat, total ash and crude protein content was determined by employing the standard method of analysis (AOAC, 2000). The total nitrogen content was estimated by Khjedal method and crude protein was calculated using the conversion factor of $\mathrm{N} \times 6.25$ of analysis. Crude fat, ash and moisture contents were estimated by employing the standard method of analysis (AOAC, 2000) using the Soxhlet extraction apparatus.

Determination of macro-nutrient content: Sodium $(\mathrm{Na})$, potassium $(\mathrm{K})$, calcium $(\mathrm{Ca})$ and magnesium $(\mathrm{Mg})$ contents of the ground sample were determined using flame photometer and atomic spectrophotometer as described by Murthy (2006). $5 \mathrm{~mL}$ of the mushroom extract solution was pipetted into a $50 \mathrm{~mL}$ volumetric flask. $1 \mathrm{~mL}$ of $26.8 \%$ Lanthanum chloride solution was added to dilute the content to the mark with $1 \mathrm{M} \mathrm{NH} \mathrm{NH}_{4} \mathrm{OAc}$ extraction solution. The solution was sprayed into the flame of the flame photometer for the determination of $\mathrm{Na}$ and $\mathrm{K}$ contents and later into the spectrophotometer flame to determine the $\mathrm{Ca}$ content. The mushroom extract solution was diluted 25-fold for the determination of $\mathrm{Mg}$ content. $2 \mathrm{~mL}$ of the solution was pipetted into a $50 \mathrm{~mL}$ volumetric flask. $5 \mathrm{~mL}$ of $5000 \mathrm{ppm} \mathrm{Sr}$ was added to fill up the mark with the $1 \mathrm{M} \mathrm{NH}_{4} \mathrm{OAc}$ solution. The solution was sprayed into the flame of the atomic absorption spectrophotometer. Phosphorus was determined colorimetrically. $10 \mathrm{~mL}$ of $\mathrm{P}$ standard series solution was put in a pipette while $10 \mathrm{~mL}$ of each extract and $10 \mathrm{~mL}$ of the blanks were added into $50 \mathrm{~mL}$ volumetric flasks. About $20 \mathrm{~mL}$ of distilled water was added and $5 \mathrm{~mL}$ of $0.8 \mathrm{M} \mathrm{H}_{3} \mathrm{BO}_{3}$ was also added. Beginning with the standards, $10 \mathrm{~mL}$ of ascorbic acid reagent was added to each flask. The flask was filled to the $50 \mathrm{~mL}$ mark with distilled water. Content was shaken well. After 1 hour, the intensity of the blue colour was measured at $880 \mathrm{~nm}$ using a colorimeter.

Determination of Micro Nutrient: Iron (Fe), copper $(\mathrm{Cu})$, manganese $(\mathrm{Mn})$ and zinc $(\mathrm{Zn})$ were determined as described by Capar et al. (1978). $10 \mathrm{~g}$ of mushroom sample was weighed into a plastic bottle and $100 \mathrm{~mL}$ of $0.1 \mathrm{M} \mathrm{H}$

1 was added and shaken for 30 minutes. This mixture was then filtered through Whatman filter paper No. 42 and $\mathrm{Fe}, \mathrm{Cu}, \mathrm{Mn}$, and $\mathrm{Zn}$ in the filtrate were determined using atomic absorption spectrometer Buck Scientific Model 205, East Norwalk, CT) (AOAC, 2005).

Determination of Antioxidants activities: P. ostreatus was analyzed for Antioxidants activities. Ascorbic Acid, flavonoid, beta carotene, lycopene, phenolic content and total soluble carbohydrate were determined using a spectrophotometer (digital spectronic 21D Spectrophotometer). Ascorbic acid content was determined using the 2, 6-dichlorophenolindophenol spectrophotometric method (Ojukwu and Nwobi, 2017). 10g of the sample slurry was weighed into a $100 \mathrm{~mL}$ volumetric flask and diluted to $100 \mathrm{~mL}$ with $3 \%$ metaphosphoric acid solution $(0.003 \mathrm{M}$ EDTA). The diluted samples were filtered using a Whatman Filter No. 3. 10mL of filtrate was pipetted into a small flask and titrated immediately with a standardized solution of 2,6-dichlorophenolindophenol to faint pink end point. The ascorbic acid content of the sample was calculated from the relationship below.

$$
m g A C=\frac{V T}{W} \times 100
$$

$\mathrm{AC}=\mathrm{mg}$ ascorbic acid per $100 \mathrm{~g}$ sample $; \mathrm{V}=\mathrm{ml}$ dye used for titration aliquot of diluted sample; $\mathrm{T}=$ ascorbic acid equivalent of dye solution expressed as $\mathrm{mg}$ per $\mathrm{ml}$ of dye; $\mathrm{W}=$ gram of sample in aliquot titrated.

Flavonoid determination was done following the method of Allen Commercial Organic Analysis (1979). $0.50 \mathrm{~g}$ of finely ground sample was weighed into a $100 \mathrm{~mL}$ beaker and $80 \mathrm{~mL}$ of $95 \%$ Ethanol added and stirred with a glass rod to prevent lumping. The mixture was filtered through Whatman No. 1 filter into a $100 \mathrm{~mL}$ volumetric flask and made up to mark with ethanol. $1 \mathrm{~mL}$ of the extract was pipetted into $50 \mathrm{~mL}$ 
volumetric flask, four drops of conc. $\mathrm{HCl}$ was added via a dropping pipette after which $0.5 \mathrm{~g}$ of magnesium turnings added to develop Magenta red coloration. Standard flavonoid solution of range $0-5 \mathrm{ppm}$ were prepared from 100ppm stock solution and treated in a similar way with $\mathrm{HCl}$ and Magnesium turnings like sample. The absorbance of Magenta red colouration of sample and standard solutions were read on a digital spectronic 21D Spectrophotometer at a wavelength of $520 \mathrm{~nm}$. The percentage flavonoid is calculated using the formula.

$$
\% \text { Flavonoid }=\frac{\text { As } x t F \times D F}{\text { Wt. Sample }} \times 100
$$

Where AS = Absorbance of sample; $\mathrm{tF}=\mathrm{t}$ Factor , DF $=$ Dilution Factor; Wt. sample $=$ weight of sample

Beta Carotene was determined by placing $1 \mathrm{~g}$ of the sample and extract in Acetone in a funnel. $5 \mathrm{~mL}$ Petroleum Ether was added along the side of the separating funnel. Petroleum ether layer was collected and measured in a spectrophotometer at 440nm. The extract and suitable standards are therefore compared at this wavelength. Lycopene content of sample was analyzed by hexane extraction and spectrophotometry. Partial least square (PLS1) regression models were developed and validated for prediction of Lycopene content from spectral data. The total phenolic compounds present in the extracts were determined with Folin-Ciocalteau phenol reagent (Singleton et al., 1999). Total soluble sugars were estimated by refluxing in 80\% ethanol (Cerning and Guilhot 1973).

\section{RESULTS AND DISCUSSION}

Proximate composition of $P$. ostreatus are presented in Table 1. Mean value of total ash in P. ostreatus was found to be $2.07 \%$. Mean value of crude protein was $12.04 \%$. Mean values of crude fiber and carbohydrates were 4.3 and $67.94 \%$ on dry weight basis respectively. Crude fat was found to be $2.95 \%$, while moisture content and oil matter were 10.7 and $89.33 \%$ on dry weight basis respectively. The high water content $(10.7 \pm 0.52)$ of $P$. ostreatus from this study was in agreement with that of Adejumo and Akinmoladun (2015) who found the moisture content of some edible and medicinal mushrooms to be between 7.12$12.36 \%$. The high content of moisture in this mushroom and others is an indication that fresh mushrooms cannot be stored for a long time as a result of microbial activities on them which is aided by their high moisture content. Conventional sources of human diets such as meat, fish, milk, and eggs contain crude protein content in wider range with crude fibre, moisture, crude fat and total ash (Micha et al., 2010). However, widespread negative concerns are recently expressed about these sources, especially about red meat, because of identified risk of heart disease, cancer, diabetes and obesity. This implies that $P$. ostreatus with good proportion of crude protein, crude fibre, moisture content, crude fat and total ash can be used as a supplement and possible replacement in human diets.

The mineral content of Pleurotus ostreatus is presented in Table 2. Data reveals that sodium content in Pleurotus ostreatus was $0.07 \%$. Calcium was found to be $0.01 \%$, Magnesium content was $0.17 \%$, Potassium was $0.66 \%$, Iron was found to be $0.0004 \%$, while Copper and Zinc were found to be 0.01 and $0.009 \%$ respectively on dry weight basis. Wildman and Medeiros (2000) reported that the daily mineral requirements of an adult man is 2-3mg of Copper, 10$15 \mathrm{mg}$ of Iron, $12-15 \mathrm{mg}$ of Zinc, $2.3 \mathrm{mg}$ of Manganese, $1000 \mathrm{mg}$ of Calcium, 400mg of Magnesium, $4.7 \mathrm{mg}$ of Potassium and 700mg of Phosphorus (Wildman and Medeiros 2000). Therefore the amount of macro and micro mineral contents in P. ostreatus, to some extent, can fulfill the daily requirements of human diet, if consumed.

P. ostreatus was analyzed for antioxidants such as flavonoid, phenol, lycopene, $\beta$ Carotene and ascorbic acid as shown in Table 3. Flavonoid content was found to be $1.8 \%$, phenol content was found to be $1.31 \%$, lycopene content was found to be $0.37 \mathrm{mg} / 100, \beta$ Carotene and ascorbic acid were found to be 356.67 and $13.93 \mathrm{mg} / 100$. Gbolagade et al. (2006) and Dundar et al. (2008) affirmed that most Pleurotus species have chemical composition such as the antioxidants which are attractive from the nutritional point of view. Gaafar et al. (2010) also reported that $P$. ostreatus can improve the antioxidant status during ageing and is capable of minimizing occurrence of prevalent age-associated disorders associated with involvement of free radicals. Their nutritional value compare to those of eggs, milk, and meat (Oei, 2003). This agreed with the present study where $P$. ostreatus was found to contain high flavonoid, phenol, lycopene, $\beta$ Carotene and ascorbic acid. This implies that $P$. ostreatus possess nutraceuticals properties which can recommend its usefulness as food supplement for heart disease, cancer, diabetes and obesity patients.

Overall the percentage content of minerals in $P$. ostreatus was less than $1 \%$, proximate composition was $33.64 \%$ and antioxidants was $66.16 \%$ (Figure 1). This showed that $P$. ostreatus has high content of antioxidants, moderate amount of proximate composition and low but overall good amount of total mineral contents. 
Table 1: Proximate composition of Pleurotus ostreatus

\begin{tabular}{ll}
\hline Proximate Composition & Content \\
\hline Total Ash $(\%)$ & $2.07 \pm 0.15$ \\
Crude Protein $(\%)$ & $12.04 \pm 1.75$ \\
Crude Fiber (\%) & $4.3 \pm 0.46$ \\
Carbohydrate $(\%)$ & $67.94 \pm 2.02$ \\
Crude Fat $(\%)$ & $2.95 \pm 0.15$ \\
Moisture Content $(\%)$ & $10.7 \pm 0.52$ \\
Oil matter $(\%)$ & $89.33 \pm 0.58$ \\
\hline \multicolumn{2}{c}{ Values are mean \pm SEM }
\end{tabular}

Table 2: Mineral content of Pleurotus ostreatus

\begin{tabular}{ll}
\hline Mineral & Mineral content $(\%)$ \\
\hline $\mathrm{Na}^{+}$ & $0.07 \pm 0.01$ \\
$\mathrm{Ca}^{2+}$ & $0.01 \pm 0.004$ \\
$\mathrm{Mg}^{2+}$ & $0.17 \pm 0.02$ \\
$\mathrm{~K}^{+}$ & $0.66 \pm 0.05$ \\
$\mathrm{P}$ & $0.15 \pm 0.01$ \\
$\mathrm{Fe}^{2+}$ & $0.004 \pm 0.0001$ \\
$\mathrm{Cu}^{2+}$ & $0.001 \pm 0.0002$ \\
$\mathrm{Zn}^{+}$ & $0.009 \pm 0.0006$ \\
$\mathrm{Mn}^{2+}$ & $0.0008 \pm 0.0002$ \\
\hline \multicolumn{2}{c}{ Values are mean \pm SEM }
\end{tabular}

Table 3: Antioxidants content of Pleurotus ostreatus

\begin{tabular}{ll}
\hline Antioxidants & Content \\
\hline Flavonoid $(\%)$ & $1.8 \pm 0.2$ \\
Phenol $(\%)$ & $1.31 \pm 0.44$ \\
Lycopene $(\mathrm{mg} / 100)$ & $0.37 \pm 0.31$ \\
$\beta$ Carotene $(\mathrm{mg} / 100)$ & $356.67 \pm 35.12$ \\
Ascorbic Acid( mg/100) & $13.93 \pm 1.43$ \\
\hline \multicolumn{2}{c}{ Values are mean \pm SEM }
\end{tabular}

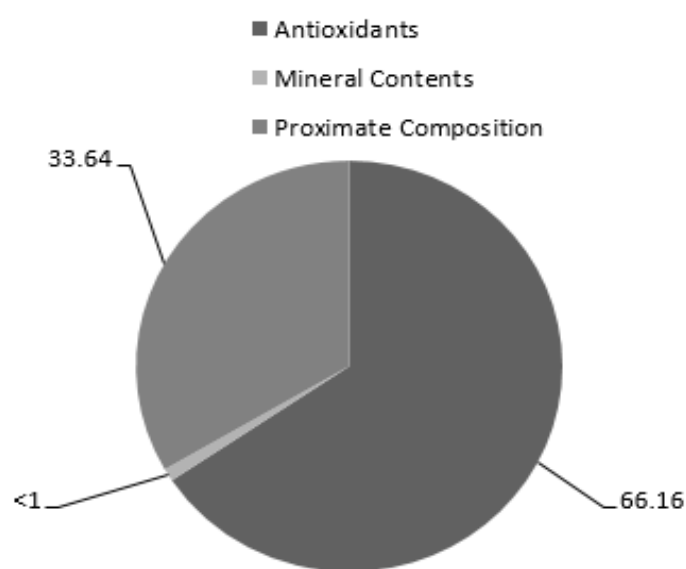

Fig 1: Percentage contents of proximate composition, mineral contents and antioxidants of Pleurotus ostreatus

Conclusion: It can be concluded from the study that $P$. ostreatus mushroom is highly nutritious, rich in proteins, low in calorific value, has very high contents of antioxidants, dietary fibres and minerals. $P$. ostreatus is therefore a suitable addition to nutritious foods that people of rural and urban areas alike covet. Raising positive awareness on its nutraceutical importance can motivate people resident mostly in urban areas to factor it into their daily diet. This may also help to protect people from diseases caused by nutrient deficiency and widespread ailments such as cancer, diabetes and obesity.

\section{REFERENCES}

Adejumo, TO; Coker, ME; Akinmoladun, VO (2015). Identification and evaluation of nutritional status of some edible and medicinal mushrooms in Akoko Area, Ondo State, Nigeria. Int J Cur Microbiol App Sci. 4(4): 1011-1028.

Allen's Commercial Organic Analysis (1979). Analysis of Analytical Methods Committee of Royal Society of Chemistry. Analytical Methods Committee Royal Society of Chemistry, 9: 222239.

AOAC (2000). Official methods of analysis. Association of Official Analytical Chemists, Washington, D.C. USA.

AOAC (2005). Official methods of analysis. 18th ed. Association of Official Agricultural Chemists, Washington DC.

Capar, SG; Tanner, J.T; Friedman, MH; Boyer, KW (1978). Multi element analysis of animal waste and sewage sludge. Environ. Sci. Technol. 12:785-790.

Ceming, J; Guilhot, J (1973). Changes in carbohydrate composition during maturation of wheat and barley kernel. Cereal Chern. 50: 220--224.

Deepalakshmi K; Mirunalini, S (2014). Pleurotus ostreatus: An Oyster mushroom with Nutritional and medicinal properties. J. Biochem. Tech. 5(2): 718-726.

Dundar, A; Acay, H; Yildiz, A (2008). Yield performances and nutritional contents of three oyster mushroom species cultivated on wheat stalk. Afr J Biotechnol. 7:3497-3501.

Gbolagade, J; Ajayi, A; Oku, I; Wankasi, D (2006). Nutritive value of common wild edible mushrooms from Southern Nigeria. Global J Biotechnol Biochem. 1:16-21

Micha, R; Wallace, S.K; Mozaffarian, D (2010). Red and processed meat consumption and risk of incident coronary heart disease, stroke, and diabetes mellitus a systematic review and metaanalysis. Circulation 121: 2271-2283

Murthy, YLN (2006). Estimation of secondary and micronutrients in soil and plants samples. Proceedings of the new dimensions in integrated management of major field crops for sustainable crop production, 5-25 October 2006. Directorate of Oil Seeds Research, Hyderabad, India. 
Oei, P. (2003) Manual on mushroom cultivation: techniques species and opportunities for commercial application in developing countries. TOOL Publications, Amsterdam. Pp 274.

Ojukwu, UP; Nwobi, SC (2017). .Determination of Ascorbic Acid Content of Some Local Fruits in Nigeria. Anal Chem Ind J. 17(1):118.

Patel, Y; Naraian, R; Singh, VK (2012). Medicinal properties of Pleurotus species (Oyster Mushroom): A Review. World J. Fungal Plant Biol. 30: 01-12.

Pourmorad, F; Hosseinimehr, SJ; Shahabimajd, N (2006). Antioxidant activity, phenol and flavonoid contents of some selected Iranian medicinal plants. Afr J Biotechnol. 5: 1142-1145.
Sánchez, C. (2004). Modern aspects of mushrooms culture technology. Appl Microbiol Biotechnol. 64:756-762.

Singleton, VL; Orthofer, R; Lamuela-Raventos, RM (1999). Analysis of total phenols and other oxidation substrates and antioxidants by means of Folin-Ciocalteau reagent. Method. Enzymol. 299:152-17.

Trudell, S.; Ammirati, J. (2009). Mushrooms of the Pacific Northwest. Timber Press Field Guides. Portland, Oregon: Timber Press. p. 134. ISBN 978-0-88192-935-5.

Wildman, R; Medeiros, D (2000). Advanced Human Nutrition. Boca Raton: CRC Press LLC. 